\title{
TRAVESTIS E O CUIDADO HUMANIZADO EM SAÚDE
}

\author{
Transvestites and Humanized Health Care
}

Travestis y el cuidado humanizado en salud

\begin{abstract}
Resumo: Com base nas diretrizes do SUS, com princípios de universalidade, integralidade e equidade, realizamos um estudo com o objetivo de identificar concepções, desejos, receios e sugestões quanto ao cuidado humanizado em saúde dirigido às pessoas travestis, no âmbito da atenção primária. O caminho teórico-metodológico foi a Hermenêutica Dialética com utilização de entrevista em profundidade e uso de "cenas”, com sete participantes. As entrevistadas relataram dificuldades quanto ao acesso e uso dos serviços de saúde. Diante das dificuldades encontradas, para a efetivação de um cuidado humanizado identificamos algumas mudanças necessárias na interlocução da saúde com a população travesti: Capacitação dos profissionais de saúde, diálogo com o movimento social, campanhas de divulgação e a aproximação com o significado da vivência de ser travesti. É urgente um trabalho efetivo na formação dos profissionais de saúde, bem como no cotidiano de nossa vida cercada por atitudes discriminatórias, em nome do compromisso com o sofrer do outro.
\end{abstract}

Palavras-chave: Travesti; Atenção Primária à Saúde; Hermenêutica, Humanização, Cuidado.

\begin{abstract}
Based on SUS guidelines, with principles of universality, completeness and equity, we carried out a study with the objective of identifying conceptions, desires, fears and suggestions regarding humanized health care for transvestites, in primary health care. The theoretical-methodological path was the Dialectic Hermeneutics using an in-depth interview and use of "scenes", with seven participants. The interviewees reported difficulties in accessing and using health services. In view of the difficulties encountered, in order to carry out a humanized care, we identify some necessary changes in the interlocution of health with the transvestite population: Training of health professionals, dialogue with the social movement, dissemination campaigns and the approximation with the meaning of the experience of being transvestite There is an urgent need for effective work in the training of health professionals, as well as in the daily lives of our lives, surrounded by discriminatory attitudes, in the name of commitment to suffering the other.
\end{abstract}

Keywords: Transvestite; Primary Health Care; Hermeneutics, Humanization, Care.

Resumen: Con base en las directrices del SUS, con principios de universalidad, integralidad y equidad, realizamos un estudio con el objetivo de identificar concepciones, deseos, temores y sugerencias en cuanto al cuidado humanizado en salud dirigido a las personas travestis, en el ámbito de la atención primaria. El camino teórico-metodológico fue la Hermenéutica Dialéctica con utilización de entrevista en profundidad y uso de escenas, con siete participantes. Las entrevistadas relataron dificultades en cuanto al acceso y uso de los servicios de salud. Ante las dificultades encontradas, para la efectividad de un cuidado humanizado identificamos algunos cambios necesarios en la interlocución de la salud con la población travesti: Capacitación de los profesionales de salud, diálogo con el movimiento social, campañas de divulgación y la aproximación con el significado de la vivencia de ser travesti. Es urgente un trabajo efectivo en la formación de los profesionales de salud, así como en el cotidiano de nuestra vida rodeada por actitudes discriminatorias, en nombre del compromiso con el sufrimiento del otro.

Palabras-clave: Travesti; Atención Primaria a la Salud; Hermenéutica, Humanización, Cuidado.

\section{Introdução}

Este escrito é um recorte de algumas das muitas reflexões sinalizadas ao término de uma dissertação que se propôs a compreender a vivência de pessoas travestis na busca por cuidados em saúde, no âmbito da atenção básica. A escolha pela Atenção Básica $(\mathrm{AB})$ para esta pesquisa se deu por alguns fatores. $\mathrm{O}$ primeiro deles é que, na organização do nosso Sistema Único de Saúde (SUS) em níveis de complexidade, a $\mathrm{AB}$ foi definida como a porta de entrada preferencial do sistema e centro ordenador das redes de atenção. Essa estruturação promove uma melhor programação e planejamento das ações e dos serviços, visando à integralidade da assistência (Brasil, 2012).

Quando a atenção básica funciona adequadamente, a população consegue resolver com qualidade a maioria dos seus problemas de saúde. Estando bem estruturada, ela reduzirá as filas nos prontos-socorros e hospitais, o consumo abusivo de medicamentos e o uso indiscriminado de equipamentos de alta tecnologia. Isso porque os problemas de saúde mais prevalentes passam a ser resolvidos nas unidades básicas de saúde, deixando os ambulatórios de especialidades e hospitais cumprirem seus ver- 
dadeiros papéis, o que resulta em maior satisfação dos usuários e utilização mais racional dos recursos existentes (Brasil, 2012).

O outro fator de relevância da atenção básica para o nosso estudo é que se têm constatado que os serviços de saúde, em vez de serem locais de acolhimento e proteção, vêm se apresentando como locais que mantêm e reproduzem as desigualdades e preconceitos da sociedade. A discriminação em alguns locais é bem perceptível, o que faz com que as travestis só busquem assistência médica em último caso, passando muito tempo com os sintomas e sem querer procurar ajuda pela forma como são tratadas nos centros de saúde (Muller \& Knauth, 2008).

Faz-se urgente a problematização da realidade vivida pelas pessoas trans, uma vez que elas são vítimas de inúmeras atitudes de preconceito e comportamentos discriminatórios, muitas vezes resultando até em assassinatos. Um dado relevante a ser discutido neste momento é o número de assassinatos a pessoas transgêneras registrados pela pesquisa da ONG Transgender Europe (TGEu) em 2016, colocando o Brasil no topo do Ranking mundial, com 868 vítimas.

Serviços de saúde "devem estar diretamente envolvidos na resposta à violência homofóbica e transfóbica existente no Brasil, uma vez que acolhem - com mais ou menos qualidade - vítimas desta mesma violência de grande magnitude”. No entanto, problemas no acolhimento da população LGBT nos serviços de saúde têm sido pauta do movimento LGBT com gestores da saúde pública (Bittencourt, Fonseca \& Segundo, 2014, p.62).

Ocorre, então, que muitas travestis, por sofrerem discriminações nas unidades de saúde, acabam não usufruindo dos serviços disponibilizados na atenção primária ${ }^{1}$, por só procurarem atendimento em casos de urgência, indo diretamente para os hospitais. Esse fator é um prejuízo para elas e para todo o sistema de saúde, na medida em que muitos problemas poderiam ser resolvidos, até preventivamente, na própria unidade básica de saúde.

Entendendo a multiplicidade das identidades e as diferentes maneiras de defini-las, precisamos primeiramente fazer um breve percurso histórico pela criação das categorias de identidades de gênero. É preciso, também, entendermos os aspectos que distinguem e os que aproximam esses conceitos identitários. A categoria de "sensibilidade sexual invertida", elaborada por Westphal, em 1869, não diferenciava homossexualidade e transexualidade, e incluía as duas como inversão entre elementos masculinos e femininos da psicologia humana. Magnus Hirschfeld, em 1910, inventou os termos Transvestitismus (travestismo) e seelischer Transexualismus (transexualidade da alma) e pensou pela primeira vez o travestismo como um fenômeno distinto da

1 Mello, Fontanella e Demarzo (2009) concluem que os termos "Atenção Básica”, "Atenção Primária” e "Atenção Primária à Saúde" podem ser utilizados como sinônimos. homossexualidade. Quase quarenta anos depois, em 1949, David O. Cauldwell chamou seu ensaio de Psychopathia trans-sexualis, mas apenas em 1953, no ensaio Transvestitism and Transexualism de Harry Benjamin, o adjetivo "transexual" foi substantivado, passando a indicar uma identidade (Bernini, 2011).

Ao falar sobre sexualidade, é importante que se compreenda a existência e a diferenciação desses dois conceitos: orientação sexual e identidade de gênero. A expressão orientação sexual diz respeito ao gênero pelo qual o indivíduo se sente atraído sexual e emocionalmente. Já se falando em identidade de gênero, essa se relaciona com o gênero (masculino, feminino, ambos ou nenhum) com o qual o indivíduo se identifica ou não se identifica. Diversas combinações podem ocorrer entre orientação sexual e identidade de gênero de forma que podemos encontrar uma expressão social de identidade que não revela, a priori, a orientação sexual. No entanto, os estereótipos em torno das orientações sexuais são comuns e até socialmente reforçados na configuração heteronormativa e cisnormativa da cultura judaico-cristã (Cerqueira-Santos et al., 2010).

Em relação à diferenciação entre as travestis e as transexuais alguns discursos apontam as transexuais como aquelas com o desejo de realizar a cirurgia de readequação sexual, e as travestis como as que se sentiriam à vontade com seu órgão genital, podendo até chegar a fazer uso dele, sendo ativas nas relações sexuais. A relação com o pênis e consequentemente a demanda ou não por cirurgias de transgenitalização são recorrentemente utilizadas como fator de distinção entre as duas identidades (Carvalho, 2018).

Porém, quando se fala "as travestis", de maneira generalista, entende-se que falamos de travestilidades, pois existem múltiplas formas de ser e sentir-se travesti. E entendendo a não viabilidade de uma classificação rígida para as identidades de gênero, neste trabalho estaremos nos referindo às pessoas que se autodeclararam como travestis, independentemente de quais transformações estas tenham se apropriado em direção ao feminino.

Nesse sentido, não existe um processo específico de construção das identidades de gênero nas transexuais. Não se deve esperar de transexuais um comportamento fixo, rígido, adequado às normas de feminilidade ou de masculinidade (Arán, Murta \& Lionço, 2009).

No percurso de construção deste estudo, ao procurarmos entender o caminho que leva à estigmatização e discriminação das travestis e sua relação com o acesso e qualidade dos cuidados em saúde oferecidos no âmbito da atenção primária chegamos às seguintes provocações: A que se destina o cuidado humanizado na voz das travestis? A atenção primária é um lugar possível para o cuidado à saúde das travestis? Com a primeira provocação discutiremos as concepções de cuidado para as travestis, e, com a segunda, expore- 
mos as possibilidades de mudanças que elas desejam no atendimento à população travesti, problematizando a atenção primária à saúde (APS) enquanto um lócus possível para a realização de um cuidado humanizado e integral.

Em meio a essas e muitas outras questões, faz-se necessário a reconstrução do sistema público de saúde, como dimensão pública do cuidado e da gestão dos processos de trabalho. E é em meio a uma reconstrução do SUS que a Política de Humanização emerge e se constitui como política pública de saúde. Nesse sentido, o Ministério da Saúde, no início de 2003, decidiu fazer uma aposta na humanização como re-encantamento do SUS. Essa temática já vinha, discretamente, adentrando os campos da saúde, como na $11^{\mathrm{a}}$ Conferência Nacional de Saúde, realizada em 2000, que tinha como título "Acesso, qualidade e humanização da atenção à saúde com controle social". De 2000 a 2002, o Programa Nacional de Humanização da Atenção Hospitalar - no compasso de outras iniciativas como a Humanização do Parto e da Saúde da Criança - iniciou ações em hospitais com o intuito de criar comitês de humanização voltados para a melhoria na qualidade da atenção e, mais tarde, com foco também no trabalhador (Pasche \& Passos, 2008).

Segundo o Ministério da Saúde o propósito da Política Nacional de Humanização (HumanizaSUS) é o de contribuir para a melhoria da qualidade da atenção e da gestão da saúde no Brasil, por meio do fortalecimento da Humanização como política transversal na rede e afirmando a indissociabilidade do modelo de atenção e de gestão (Brasil, 2012). Temos vários compromissos do governo relativos ao tema da saúde da população LGBT, como a carta dos diretos dos usuários da Saúde (2011), o Plano Nacional de Enfrentamento da Epidemia de AIDS e das DSTs entre Gays, HSH e Travestis (2007), e a Política Nacional de Saúde Integral de Lésbicas, Gays, Bissexuais, Travestis e Transexuais - LGBT (2013). A garantia do direito à saúde para a população trans, superando a violação de seus direitos humanos rumo à promoção da equidade no sistema de saúde, requer, necessariamente, que se avance na perspectiva da democratização dos direitos humanos, mediante o reconhecimento das diversas possibilidades de constituição humanas e do exercício da sexualidade (Lionço, 2008). Porém, ainda há muito o que fazer para que possamos ver acontecendo na prática o respeito e o atendimento humanizado de que os documentos tanto falam.

Diante da importância de pesquisas no tocante à saúde da população travesti, e tendo como base as diretrizes do SUS, com princípios de universalidade, integralidade e equidade, realizamos este estudo com o objetivo de identificar concepções, desejos, receios e sugestões quanto ao cuidado humanizado em saúde dirigido às travestis na cidade de Natal.

\section{Percurso Metodológico}

O caminho teórico - metodológico escolhido é a Hermenêutica Gadameriana aliada aos princípios dialéticos. É importante registrar que Gadamer (1960/2002) se aproxima da dialética quando assegura que a compreensão só é possível pelo estranhamento, pois a necessidade de entendimento nasce do fracasso da transparência da linguagem e da própria incompletude e finitude humana. As colaboradoras desta pesquisa foram sete pessoas travestis da cidade de Natal. O critério de inclusão das participantes foi de ter buscado e/ou ter sido atendida em algum serviço de saúde da atenção básica de Natal e se autodeclararem pessoas travestis.

Utilizamos, para o acesso às narrativas das colaboradoras, a entrevista em profundidade com roteiro, e a oficina com o uso de "cenas". As oficinas em grupo com utilização de "cenas" projetivas atendem ao intuito de aprofundamento dos dados da entrevista. Segundo Paiva (2005), o uso de cenas são ferramentas para conscientização, ação, invenção e circulação de repertórios discursivos (e não discursivos) de grupos e indivíduos, que podem resultar em mobilização individual e social para promoção da saúde.

As cenas foram construídas com duas das participantes, após a entrevista, da seguinte maneira: primeiramente houve um momento de relaxamento e preparação, onde as entrevistadas foram convidadas a fechar os olhos e se deixar envolver por uma cena que criaram mentalmente a partir das instruções: "Construa uma cena onde existe uma paciente travesti que procura atendimento em alguma Unidade Básica de Saúde, nessa unidade ela é mal atendida. Crie o roteiro, a situação em que você chega e as características do seu atendimento: $O$ que você sente, quem está com você, como age, como as pessoas que você tem contato também agem. Descreva com o máximo de detalhes o que aconteceu..."

Foi pedido, após alguns minutos, que as entrevistadas abrissem os olhos e relatassem a cena em um papel com o maior detalhamento possível. Esgotado este momento, o processo se repetiu, agora com a orientação de uma cena onde elas foram bem atendidas. Quando todas terminaram, o exercício foi compartilhado em uma discussão em grupo.

Os contatos com as entrevistadas foram feitos através dos encontros estaduais e nacionais de travestis, que ocorreram em Natal no ano de 2013 que são encontros onde se reúnem pessoas travestis e transexuais, para discutir garantias de direitos e melhorias para a população trans - e também da "Associação de Travestis Reencontrando a Vida” (ATREVIDA), associação de pessoas travestis e transexuais sem fins lucrativos da cidade de Natal. Foram indicados, através da presidente da associação, alguns nomes para possível contato de entrevista, o que deu início ao método "bola de neve”. A cada entrevistada 
era pedido o contato de outra travesti, e que pudesse ser falado o nome de quem tinha indicado o contato.

Entrevistamos um total de sete participantes, com idades que variaram de 28 a 52 anos. Em relação ao nível de escolaridade, duas possuíam ensino médio incompleto, duas ensino médio completo, duas superior incompleto e uma superior em andamento. As profissões que exerciam eram: cabeleireira, cantora, vendedora, manicure, profissional do sexo, cozinheira e militar reformada. Os nomes das entrevistadas foram alterados; utilizamos codinomes para evitar a identificação pelo perfil das mesmas. A escolha dos codinomes se deu a partir da fala de uma das entrevistadas, onde a mesma relatou "fechar o olho e se imaginar uma Naomi Campbell, uma Gisele Bündchen”. A pesquisa foi aprovada no comitê de ética da UFRN, sob o número do CAAE: 16629913.6.0000.5537, e parecer número 493685.

O local do acesso às narrativas das colaboradoras foi estabelecido de acordo com a conveniência das entrevistadas, garantindo condições adequadas, a não interrupção e a privacidade. Algumas entrevistas foram realizadas nas casas das participantes e outras em seus locais de trabalho. Realizou-se em diferentes bairros da cidade de Natal. A referida cidade é capital do Rio Grande do Norte e possui uma população, segundo último censo do Instituto Brasileiro de Geografia e Estatística - IBGE (2010), de 803.739 pessoas. Apresenta, ainda, $61.8 \%$ de domicílios com esgotamento sanitário adequado, 44.7\% de domicílios urbanos em vias públicas com arborização e $16.5 \%$ de domicílios urbanos em vias públicas com urbanização adequada.

As participantes foram informadas da pesquisa no primeiro contato, no qual os objetivos do projeto foram esclarecidos a partir da apresentação do Termo de Compromisso Livre e Esclarecido, respeitando as regras éticas em conformidade com a Lei $\mathrm{n}^{\circ}$ 466/2012. Todas as entrevistas foram gravadas com a anuência das entrevistadas, sendo posteriormente transcritas pela própria pesquisadora. As transcrições foram feitas literalmente. O que foi transcrito era exatamente igual ao que havia sido falado pela entrevistada; leiam-se: expressões faladas, pausas, erros, etc.

Em termos de análise das entrevistas utilizamos o método de interpretação de sentidos, baseando-se em princípios hermenêuticos-dialéticos que buscam interpretar o contexto, as razões e as lógicas de falas, ações e inter-relações entre grupos e instituições (Gomes, Souza, Minayo, Malaquias \& Silva, 2005).

$\mathrm{Na}$ trajetória analítico interpretativa, percorremos os seguintes passos: (a) leitura compreensiva, visando impregnação, visão de conjunto e apreensão das particularidades do material da pesquisa; (b) identificação e recorte temático que emergem dos depoimentos; (c) identificação e problematização das ideias explícitas e implícitas nos depoimentos; (d) busca de sentidos mais amplos (sócio-político- -culturais), subjacentes às falas dos sujeitos da pesquisa; (e) diálogo entre as ideias problematizadas, informações provenientes de outros estudos acerca do assunto e o referencial teórico do estudo; (f) elaboração de síntese interpretativa, procurando articular objetivo do estudo, base teórica adotada e dados empíricos. Tal trajetória analítico-interpretativa busca desvendar a lógica e os sentidos submersos nas ações (perspectiva hermenêutica), confrontando tais ações com o plano das intenções/idealizações e com o seu contexto (perspectiva dialética). Temos assim, uma análise hermenêutico-dialética das narrativas.

\section{A que se destina o Cuidado Humani- zado na voz das Travestis?}

Diante da reconstrução da saúde baseada nos conceitos da Política Nacional de Humanização (PNH), nos perguntamos: O que pensam nossas colaboradoras sobre um cuidado humanizado em saúde? Como desejam ser atendidas? Para iniciar nossa conversa com elas sobre esse tema trazemos inicialmente um pequeno fragmento de entrevista, no qual uma das entrevistadas, ao ser perguntada como deve ser um atendimento em saúde, nos revela alguns dos aspectos que a PNH busca implementar:

Humanizado. Porque é muito fácil humaniza SUS, mas na verdade o SUS não tá humanizado ainda, tem que ser todo dia, todo dia humanizar os funcionários de saúde. (...) Diálogo. Só em você respeitar, me respeitar enquanto gênero. Vê, chegou a travesti: "Como é que você gostaria de ser chamada na hora que for atender?" (Fragmento de entrevista - Gisele Bündchen).

Para Gisele, a humanização passa por questões centrais como diálogo e respeito. A entrevistada retrata esse respeito desejado representado pelo interesse do profissional em usar o seu nome social. E ainda ressalta que muito se fala em humanização, mas alerta que na prática temos que enfrentar uma luta diária se quisermos chegar lá.

Corroboramos o que afirma Nogueira da Silva (2014, p.20) quando afirma que Humanizar é entendido como "garantir à palavra sua dignidade ética", ou seja, possibilitar que o sofrimento a dor e o prazer possam ser expressos pelos sujeitos em palavras e reconhecidos pelo outro, uma vez que "as coisas do mundo só se tornam humanas quando passam pelo diálogo com os semelhantes". Não é possível falarmos em cuidado humanizado sem qualidade na comunicação. Dentre as principais prioridades nas quais a PNH tem investido descritas pelo Ministério da Saúde, encontra-se: Valorização da dimensão subjetiva e social em todas as práticas de atenção e gestão no SUS, fortalecendo o compromisso com os direitos do cidadão, destacando-se o respeito às questões de gênero, etnia, raça, orientação sexual e às populações específicas (índios, quilombolas, ri- 
beirinhos, assentados, etc.) (Pasche \& Passos, 2008).

Cabe ressaltar, nesse momento do percurso, que ao falarmos de Cuidado Humanizado estamos adotando a conceituação de Ayres, na qual afirma que cuidar de alguém é mais do que construir um objeto e intervir sobre ele. "O cuidado busca ser um 'espaço relacional', que trata o assistido também como sujeito" (Ayres, 2002, p.5). Nesse sentido, vejamos alguns discursos que falam da concepção de cuidado para as nossas colaboradoras, obtidos a partir das respostas que revelam suas opiniões acerca do que elas entendem por um atendimento em saúde:

Com respeito, não importa se é travesti, nada. Que tenha mais respeito com a pessoa que tá ali, porque ela tá precisando de ajuda, de um atendimento bom, pelo menos pra se sentir meIhor. Porque você chega doente e tem um atendimento ruim você fica pior ainda. Isso é em geral, não só com a gente não, pra todo mundo (Fragmento de entrevista - Julia Roberts).

Um atendimento de saúde deveria ser comum, igual a qualquer um outro. (...) Quando chega um gay, uma travesti principalmente, porque as pessoas ligam logo, as pessoas generalizam que todas as travestis fazem programa, entendeu? Aí já é chacoteada, as pessoas ficam se cutucando. E assim, eu acho que a gente só deveria ser respeitada igual às outras pessoas são, ser tratadas igual as outras pessoas (Fragmento de entrevista - Angelina Jolie).

Uma maneira de enxergar as travestis nos permite problematizá-las como expressão de resistência ao biopoder, de enfrentamento aos processos seculares de normatização e a emergência de novas expressões existenciais que se efetuam como estilísticas da existência, confirmando a leitura feita por Foucault de que onde há poder, há resistência (Peres, 2008).

As normas regulatórias de gênero produzem performaticamente sujeitos que, a priori, deveriam ser sujeitos de direitos, mas, por não condizerem com as normas que fazem uma relação direta entre corpo-sexo-gênero-sujeito de direito, sofrem um processo de estigmatização e discriminação que torna essas vidas desviantes, à margem da sociedade, criando barreiras ao seu acesso de saúde integral, o que torna as mulheres trans mais vulneráveis social, individual e programaticamente ao adoecimento. Tal vulnerabilidade, porém, pode ser aumentada ou diminuída pelos elementos que compõem a dimensão programática, ou seja, se a qualidade no atendimento, a acessibilidade a ele e o preparo do profissional de saúde levam em conta a vulnerabilidade social que produz a vulnerabilidade individual ao adoecimento (Tagliamento, 2012).

Vimos, pois, o Cuidado ser apresentado pelas nossas entrevistadas a partir dos seguintes sentidos: cuidado como humanização, diálogo, respeito e igualdade. Elementos mais que necessários para a realização de um Cuidado como o proposto por Ayres (2004): "uma interação entre dois ou mais sujeitos visando o alívio de um sofrimento ou o alcance de um bem-estar, sempre mediada por saberes especificamente voltados para essa finalidade” (p.74).

Cabe destacarmos dois aspectos frequentemente relacionados à ideia de cuidado, e estreitamente ligados à questão da escuta e acolhimento, são o vínculo e a responsabilidade. A ideia de vínculo remete a algumas práticas e atitudes fundamentais para a realização do cuidar: abrir mais espaço para os usuários como verdadeiros sujeitos, e não como objetos de intervenção; mais continência e continuidade no serviço às diferentes demandas de indivíduos e comunidades; promover um efetivo envolvimento de profissionais e usuários ou comunidades com os processos de cuidado (Ayres, 2009).

Por sua vez, o acolhimento é condição necessária para a efetivação do cuidado, no sentido que adotamos, de uma atenção à saúde que não seja movida tão somente pela razão instrumental da racionalidade da biomedicina. Teixeira (2005) traz um modelo de acolhimento onde a autonomia do usuário seria respeitada e incentivada, e os seus saberes não seriam engolidos como em um modelo não-humanizado de saúde: "um acolhimento dialogado, isto é, como uma técnica de conversa passível de ser operada por qualquer profissional, em qualquer momento de atendimento" (p.592).

$\mathrm{O}$ acolhimento é uma das diretrizes da $\mathrm{PNH}$ e tem se tornado sua face mais visível, especialmente na Atenção Primária à Saúde (APS), pelas consequências diretas que pode determinar no acesso dos usuários como uma mudança no processo de trabalho, a fim de atender todos aqueles que buscarem o serviço de saúde. O conceito de Acolhimento tem sido capturado e instrumentalizado de forma reduzida, como se ele fosse uma tecnologia utilizada em um lugar e um horário definido, geralmente colocado apenas nas portas das urgências ou dos serviços de saúde, desconectado do restante da atenção. Este tipo de redução do conceito implica a perda de sua potência e de seu significado e resulta numa postura do profissional que diz "Não" para o paciente, que não consegue incluir toda a dimensão do sofrimento do paciente, que desvaloriza sua percepção sobre a situação de saúde vivida naquele momento e que se limita a direcioná-lo para os atendimentos disponíveis na instituição (Brasil, 2016).

Um exemplo da importância de um acolhimento adequado feito por uma profissional que seria só intermediária para a consulta encontra-se no fragmento a seguir:

Até eu chegar no hospital do câncer não tinha caído a ficha, mas quando a menina, eu entreguei o papel pra ela, e ela me encaminhando, marcando pra eu fazer a quimioterapia, radioterapia, aí caiu a ficha, eu caí em prantos... 
né? E a menina atendente me acolheu, sabe? Me abraçou, e tentou, ela fez o papel de uma psicóloga. Na hora não tinha ninguém pra me atender, até então não tinha caído a ficha, meu mundo desmoronou naquela hora, e foi muito bacana, porque eu percebi que as meninas são treinadas pra amparar um paciente que muitas vezes chegam lá e cai a ficha naquela hora (Fragmento de entrevista - Gisele Bündchen).

No relato acima, a atendente pôde participar do processo de atenção, transportando o acolhimento humanizado para outros setores do serviço além do consultório médico. Por trás do conhecido jargão da "escuta e acolhimento" há elementos fundamentais para o cuidado. Ayres (2009) nos fala que é preciso ouvir mais. Ouvir mais porque o relato das pessoas, que é tão importante para o raciocínio diagnóstico e terapêutico, foi sendo substituído por um arsenal de tecnologias diagnósticas e terapêuticas. É preciso também ver mais. No sentido de enxergar aquilo que não é falado, mas que é dito através de gestos, olhar, postura, respiração. E é preciso tocar mais. Tocar um local dolorido, que causa desconforto, para que o usuário fale de forma mais potente e ajude no processo diagnóstico e de intervenção.

O fato é que, apesar de existir uma nova concepção de cuidado, onde o sujeito tem autonomia sobre a sua saúde, o domínio da medicina sobre o corpo e sobre as verdades no agir correto com esse corpo ainda são representações fortes na nossa sociedade, e por vezes toma o lugar de outras formas de comunicação. Percebemos essa relação na fala de uma das entrevistadas onde ela acredita que um bom atendimento é aquele onde o médico, legitimado pela ciência, lhe diz o que é preciso fazer, enquanto ela a escuta e segue as suas recomendações.

Um atendimento bom, um atendimento que $o$ médico possa explicar várias coisas, várias doenças, isso ele explica, ter sempre o seu parceiro certo, na época que eu fiz meu exame de HIV, o médico perguntou: "Você tem seu parceiro?" Na época que eu não tinha, graças a Deus deu tudo bem. "Você agora procure uma pessoa certa pra você não pegar certas doenças" E hoje tô ai (Fragmento de entrevista - Beyoncé).

É possível pensar que o "aconselhamento" do médico aqui citado, ou sua "prescrição" pode ser recebida como atenção, e, portanto, um aspecto desejado do cuidado. Outro instrumento de acesso às narrativas das colaboradoras foi o uso das cenas como já explicitado na metodologia. O objetivo foi aprofundar as nossas observações em relação às concepções e desejos das travestis quanto ao cuidado humanizado em saúde dirigido a elas. O uso das cenas possibilita que o participante, ao realizar projeções, possa aprofundar percepções, revelando ainda os medos e angústias relacionadas à temática em questão.

Durante a realização das cenas foi solicitado que as participantes imaginassem uma situação em que fossem mal atendidas em um serviço de saúde. Em seguida, foi pedido que elas descrevessem, com o máximo de detalhes, e depois compartilhassem com o grupo. A segunda cena consistia na mesma instrução, mas foi pedido que elas se imaginassem em um bom atendimento. Vejamos o relato escrito das participantes ao imaginarem a primeira cena (atendimento ruim):

Nesse caso a primeira coisa que nos constrange é o olhar dos próprios pacientes em espera, que muitos olham meio torto para a gente. Daí vem o olhar de quem nos atende e até dos médicos. $\mathrm{O}$ primeiro exame que eles mandam a gente fazer é o de HIV, como se todos os gays ou lésbicas ou travesti tivessem o vírus, para mim isso já é falta de respeito (Naomi Campbell).

Ao chegar no posto de saúde fui mal atendido pelo médico de plantão. Eu estava com a minha mãe e eu mim senti muito constrangida então eu falei com a minha mãe e ela foi conversar com o médico, e ele foi muito educado com ela e depois foi até mim e me pediu desculpa. Eu com muita raiva desculpei, mas a minha vontade era de falar muitas coisas (Nicole Kidman).

As participantes, portanto, confirmaram alguns aspectos já discutidos nos relatos das entrevistas, quando descrevem, na imaginação da cena onde elas são mal atendidas, o olhar discriminatório que elas enfrentam ao procurar atendimento em saúde.

Muller (2007) também encontrou em sua pesquisa a associação direta das pessoas travestis com o HIV como um elemento discriminador. Elas percebem e relacionam certas atitudes dos profissionais com a ideia de que seriam portadoras do vírus. Um dos motivos para essa discriminação pode ser a falta de informação sobre o modo de transmissão do HIV. Outro motivo pode ser a associação das pessoas travestis com a prostituição e com comportamentos sexuais desviantes da heteronorma, sendo enquadradas na concepção ultrapassada de "grupos de risco”. Segundo Muller e Knauth (2008), as pessoas travestis são mais vulneráveis devido a alguns fatores socioeconômicos, como: a baixa escolaridade, a condição de pobreza que caracteriza o grupo e a estigmatização social.

As medidas de prevenção dirigidas a pessoas travestis muitas vezes não se efetivam porque o contexto em que elas vivem não muda. Segundo Pelúcio (2009), seu constante risco não é a AIDS, doença que pode levar até dez anos para se manifestar, mas sim o estigma, que as expulsa de casa e da escola e limita as suas possibilidades no mercado de trabalho. As demandas específicas 
das pessoas travestis em relação à saúde são distintas daquilo que o sistema de saúde público lhes oferece

Nesse sentido, Carvalho (2013) afirma que as políticas de enfrentamento à epidemia da AIDS se consolidam como o principal canal de interlocução do movimento. Fato que tem, por parte do Governo, uma preocupação implícita com o avanço da epidemia. Porém, os resultados da pesquisa indicam uma maior relevância das mortes de pessoas travestis e transexuais por assassinatos que poderiam ser considerados crimes de ódio, e não por decorrência da AIDS. Com isso, o autor não pretende negar os altos índices de infecção pelo HIV nessa população, mas sim lembrar que muitas delas morrem com AIDS e não em decorrência da AIDS.

Em que pese a riqueza do movimento social em AIDS e suas contribuições para pensarmos os avanços e desafios do SUS, evidencia-se também a necessidade de "descolar” as ações em saúde para o público LGBT do foco único da prevenção de HIV/ AIDS (Bittencourt, Fonseca \& Segundo, 2014). Já na segunda cena, podemos ver como elas idealizaram um bom atendimento:

Ser bem atendido em qualquer ambiente é sempre bom, principalmente em ambientes que os profissionais já devam esse respeito a todos com quem e para quem eles trabalham, sem julgar pela nossa cor, religião e orientação sexual. É muito bom ser tratado com respeito! (Naomi Campbell).

Ao procurar um atendimento em uma unidade de saúde fiquei surpreso com o atendimento que eu recebi. Logo de entrada já me chamaram pelo o meu nome social, ao chegar na sala de atendimento o enfermeiro que me atendeu perguntou se eu gostaria de ser chamada pelo meu nome social e me tratou com educação e muita agilidade. Por isso essa unidade de saúde está de parabéns e eles são bastante competentes (Nicole Kidman).

Percebemos o desejo das participantes de um acolhimento igualitário, sem julgamentos, com a devida utilização do nome social. A necessidade de serem atendidas com respeito é aspecto central no cuidado às travestis aqui apresentado.

As cenas reforçam a necessidade de profissionais comprometidos com a dor do outro, capazes de lidar com seus preconceitos de forma que eles não afetem ou constranjam aqueles que precisam de cuidados. Müller (2007), em sua pesquisa de especialização a respeito da percepção de pessoas travestis sobre o atendimento em saúde, ressalta que, durante a graduação (no seu caso, de enfermagem), há uma grande preocupação com a questão da técnica, mas não com o "outro" que se apresenta com todas as suas angústias e medos. Ele identifica que os profissionais não estão preparados para receber pessoas que fogem às normas de gênero.
Ayres (2004, 2007, 2009) sustenta a ideia de projeto de felicidade como uma espécie de horizonte normativo implicado na noção de cuidado. Isto é, o projeto de felicidade é a referência que nos permite compreender o que as pessoas estão buscando em nossas capacidades instrumentais e, no mesmo movimento, permite às pessoas compreenderem o que temos efetivamente para oferecer a elas com nossas tecnologias. Assim, profissionais e usuários, ou comunidades, podem fazer as melhores escolhas para alcançar os maiores benefícios no cuidado de sua saúde.

Então, se faz necessário, quando cuidamos, saber qual é o projeto de felicidade do usuário, isto é, que concepção de vida bem-sucedida orienta os projetos existenciais dos sujeitos implicados nesse processo. Porém, raramente perguntamos quais são os projetos de felicidades dos usuários, e muito menos participamos efetivamente dessa construção (Ayres, 2004). Fazendo um paralelo dos discursos com os princípios do SUS, entendemos como o cuidado está aí implicado. O princípio da universalidade nos impulsiona a construir o acesso para todos, o da equidade nos exige pactuar com todos o que cada um necessita, e a integralidade nos desafia a saber e fazer "o quê", e "como" pode ser realizado em saúde para responder universalmente às necessidades de cada um (Ayres, 2009).

Talvez não seja demais lembrar aqui que os problemas enfrentados pela população LGBT no que diz respeito ao acesso a serviços de saúde são ainda mais dramáticos nos casos de travestis e transexuais. Não só por reivindicarem atendimento especializado para demandas que não se colocam para outros segmentos populacionais (alterações corporais associadas ao uso de hormônios e silicone, por exemplo), mas também pela intensidade da transfobia que costuma incidir sobre estes dois grupos identitários, especialmente quando também são discriminados a partir de outros marcadores sociais, como níveis de renda e de escolaridade, raça/ cor e aparência física, entre outros. Nesses termos, pode-se apontar que travestis e transexuais correspondem ao público, no conjunto da população LGBT, que mais intensamente sente a escassez de políticas de saúde específicas e, paralelamente, o que mais se beneficiará de tais ações quando forem efetivadas (Mello, Perilo, Braz \& Pedrosa, 2011). Porém, essas mudanças só existirão a partir de uma luta diária, como um novo horizonte aos problemas vividos diariamente no contexto da saúde. Como nos trouxe Gisele:

$\mathrm{Eu}$ acho que o SUS, por mais problema que exista é ainda o que nós temos. $O$ que nós temos é que trabalhar para que seja um SUS de melhor qualidade. Eu não posso jogar pedra naquilo que eu tenho em mãos (Fragmento de entrevista - Gisele Bündchen). 
O cuidado, na fala de Gisele, toma outro lugar quando ela nos convida a reflexionar também sobre a forma que nós temos cuidado do nosso fazer e do nosso sistema público de saúde. Butler (2002) proporá uma reversão analítica em que os corpos abjetos passam a serem problematizados como agentes de resistência e de enfrentamento ao biopoder. De um corpo despotencializado e fraco surge um corpo empoderado e forte, guerreiro e reivindicador de direitos, que passa a participar das esferas de poder e descobre nas ações do coletivo a possibilidade de ser respeitada e tratada como cidadã. Seu enfrentamento à heteronormatividade desestabiliza e coloca em questão a ordem normativa e disciplinar que é imposta pelo sistema sexo/gênero/desejo/ práticas sexuais. (Peres, n.d, p.880).

Para Dumaresq (2016), diante da consciência do problema, posicionar-se diante dos seus pares profissionais para aperfeiçoar os processos de atendimento, contribuir com o conhecimento clínico e terapêutico é uma saída política e moralmente válida. Todas as outras alternativas são conformismo ou omissão.

\section{A APS: um Lugar Possível para o Cui- dado Humanizado às Travestis?}

Neste tópico, procuramos identificar quais eram as mudanças necessárias para que o serviço de saúde melhor atendesse ao público travesti. Então, surgiram respostas nos seguintes sentidos: Era preciso haver capacitação dos profissionais, diálogo com o movimento social, campanhas de divulgação para travestis, e aproximação com o ser travesti.

A PNH trouxe uma proposta de valorização dos diferentes sujeitos implicados no processo de produção de saúde: usuários, trabalhadores e gestores, que deve ser implementada com base nos seguintes princípios: transversalidade, qualificando a comunicação no sistema; indissociabilidade entre atenção e gestão, garantindo a integralidade do cuidado ao identificá-lo com os processos de trabalho e produção de saúde; protagonismo, corresponsabilidade; e autonomia dos sujeitos e coletivos. Este último se relaciona diretamente com o entendimento do trabalho como forma de produção de sujeitos, assumindo que a autonomia destes nos processos de gestão e cuidado garante maior efetividade nas mudanças do sistema de saúde (Scholze, Duarte Júnior \& Silva, 2009). Vejamos algumas falas que reclamam por mudanças na postura dos profissionais:

Os profissionais de saúde fossem mais capacitados. Fossem humanizados. Eu acho que se você começar a trabalhar com capacitação buscando diálogo com o movimento social. Que as faculdades, universidades, os médicos, assistentes sociais, psicólogos tentassem se aproximar mais dos movimentos sociais. Digamos, em vez de uma entrevista solitária entre eu e você, botasse uma travesti numa sala de aula e dialogasse com todo mundo, entendeu? $\mathrm{Eu}$ acho que isso multiplicaria muito mais. Porque surge efeito, pode não surgir efeito em um, dois, mas aquela sementinha vai ficar plantada (Fragmento de entrevista - Gisele Bündchen).

Eu acho que deveria ter uma capacitação, eu acho que já deveria vir regularizado, em relação a nome social, em relação a tudo. (...) $O$ que os profissionais deveriam ser eram capacitados, e não a gente ficar implorando pra ela me chamar de mulher (Fragmento de entrevista - Angelina Jolie). Porque acho que falta capacitação também do governo, do órgão público, de capacitar essas pessoas, de orientar, não adianta ter, tem várias leis aqui no nosso estado que nos protegem, mas se o profissional não é capacitado, é complicado (Fragmento de entrevista - Naomi Campbell).

A capacitação dos profissionais foi o elemento de mudança que mais apareceu nas falas das entrevistadas. A capacitação aparece tanto em relação específica ao uso do nome social pelos profissionais, como também em um sentido mais amplo, na capacitação através do diálogo entre os profissionais, a universidade e o movimento social. O que podemos perceber, e que corrobora a opinião da entrevistada, é que há desarticulação entre o SUS, a universidade e o movimento social. Sabemos de iniciativas nessas três instâncias no tocante a melhoria de vida da população trans, porém, são iniciativas isoladas, que se dialogassem entre si surtiriam ações mais efetivas.

Um entrave para a problemática da capacitação dos profissionais seria a falta de abordagem dos temas relativos à diversidade sexual nos currículos da formação inicial dos/as profissionais. A defasagem na formação inicial aconteceria não apenas com agentes comunitários de saúde, mas também enfermeiros/as, médicos/as e outros/ as profissionais (Bittencourt, Fonseca \& Segundo, 2014). Em se tratando especificamente as questões de diversidade de identidades de gênero, a Red por la Despatologización de las Identidades Trans del Estado Español publicou, em 2010, um Guía de Buenas Prácticas para la Atención Sanitaria a Personas Trans em el Marco del Sistema Nacional de Salud. Este documento, em contraposição ao SOC, sugere a "elaboração de protocolos alternativos e não patologizantes na atenção sanitária a pessoas trans" (Borba, 2014)

Tendo essas premissas como pano de fundo, o Guía de Buenas Prácticas defende que as funções dos profissionais de saúde em programas de transgenitalização incluam, dentre outros: Ter estudado sexologia ou psicoterapia em uma perspectiva não patologizante ou fazer parte de um grupo de estudos de gênero (estudos feministas, igualdade de gênero, etc.); (Red por la despatologización de las identidades trans del estado español, 2010, 27). 
Porém, como nos trouxe a fala de Naomi, a existência de documentos que abordem a questão da discriminação da população nos espaços de saúde não é garantia de efetivação dos seus direitos. No dia a dia, elas esbarram na falta de preparo dos profissionais de saúde e na pouca estrutura e aceitabilidade dos serviços em recebê-las. Segundo Schraiber (2012), existe uma autonomia relativa entre a política e a prática profissional: o descompasso entre o que está dado em um plano como proposta (intenção) de ação e os saberes e ações concretamente realizados em práticas produtivas, operatórias da assistência, na esfera dos serviços. "Em outros termos, a proposta como plano é situação distinta daquela como tecnologia, isto é, saber operatório do trabalho profissional” (p.2638).

Embora serviços tenham sido efetivamente planejados e implantados, observando-se movimentos de ampliação e também de retração das redes, há estudos que mostram além das dificuldades na realização da lei no plano das práticas profissionais, um desempenho baseado em crenças, julgamentos morais e bases religiosas, que dizem respeito a aspectos pessoais, mas recobertos pela autoridade técnico-científica, dando legitimidade à autoridade profissional em saúde. É necessário, pois, que se amplie o conhecimento sobre os obstáculos à politização das práticas (Schraiber, 2012). Ter profissionais qualificados é de suma importância para o acesso do público trans aos serviços de saúde. Porém, acesso e qualidade são duas variáveis que andam em conjunto, pois a baixa qualidade leva a uma barreira ao acesso à saúde. $\mathrm{O}$ despreparo dos profissionais começa desde a chegada ao serviço, quando estes emitem um olhar diferenciado para aquele sujeito resultado de uma forma deficitária no que tange a essas questões e de um modelo biomédico ainda reducionista que pouca atenção dirige para as questões existenciais e emocionais do processo saúde doença, apesar do inegável e crescente movimento de reumanização na saúde que vêm atingindo também a formação dos profissionais (Tagliamento, 2012).

Outra recomendação surgida nas falas para uma melhoria no atendimento do público travesti foi a necessidade de haver campanhas de incentivo ao uso do serviço de saúde. Naomi, que participa da Associação ATREVIDA, diz nunca ter visto campanhas nesse sentido.

Então se melhorarem o atendimento, fizerem campanhas de incentivo, em rádio, televisionada, panfletagem, outdoor, principalmente em relação à prevenção de DST's em geral, porque muitas mesmo vivem na rua à mercê, porque o trabalho não abre espaço. (...) Eu nunca vi campanhas de divulgação pra travesti procurar unidade básica aqui em Natal, nunca vi... pra procurar nada na verdade, pra se cuidar (Fragmento de entrevista - Naomi Campbell).
Da mesma forma que as normas existentes, cartazes direcionados à travestis podem não surtir muito efeito no seu dia a dia, pois o seu contexto de vida não mudará. As estigmatizações continuarão a acontecer se não ocorrerem medidas mais efetivas e que trabalhem em conjunto. Em relação aos profissionais, nas unidades de saúde trabalham pessoas com origens sociais e formações distintas, e desconsideram-se os aspectos culturais envolvidos no processo de cada um e na sua relação com o trabalho. Portanto, cartazes e cartilhas, ensinando como se deve tratar alguém travesti ou transexual não entrará por osmose nas atitudes desses profissionais, podem não fazer sentido para eles, pois são apresentados de forma prescritiva, acreditando que o simples contato com aquelas informações poderá mudar seus valores e suas práticas.

As práticas dos profissionais serem vistas como independentes das questões sociais, econômicas, políticas ou culturais, faz com que sua qualidade seja baseada apenas na dimensão técnico-científica de seus saberes. Por isso, segundo Schraiber (2012), foi feito um grande investimento na tentativa de mudar o desempenho concreto dos profissionais a partir de reformas educacionais, como se, com a formação, os profissionais pudessem transformar suas práticas e torná-las mais éticas ou democráticas, a fim de garantirem o melhor acerto técnico. Assim, um movimento nuclear muito importante da Saúde Coletiva tem sido o de politizar o campo da Saúde, seja enquanto Saúde Pública ou Medicina. Politizar no sentido de "rearticular ao social os referenciais particulares da Saúde, calcados na epidemiologia tradicional e na biomedicina, mostrando que tais práticas técnicas são também e antes de tudo práticas sociais, (re) produzindo o social de modo particular na esfera técnica de atuação” (p.2638).

Romano (2008) nos traz que estratégias diferenciadas de acolhimento devem ser implementadas no lidar com diversidades. Para o autor, a preocupação em implementar políticas de saúde que abarquem as necessidades específicas das travestis é apostar no respeito à diferença e na valorização da dignidade humana. Portanto, se a concepção de gênero que orienta as políticas públicas não se liberar dos pressupostos biologizantes, não terá como ampliar e incluir sujeitos que hoje estão fora dos seus marcos (Bento, 2012). Nesse sentido, vejamos o recorte:

E fora que os profissionais deveriam se conscientizar que nós travestis precisamos também de hormônios, a gente tem instintos femininos e não era pra tá se drogando sozinha (Fragmento de entrevista - Angelina Jolie).

A implantação de políticas públicas que incluam o tratamento hormonal para as travestis é também tema urgente para as travestis, que pedem por um acompanhamento adequado com endocrinolo- 
gistas. Acompanhamento que deveria ser disponibilizado pela atenção básica, pois, segundo o Ministério da Saúde, ela orienta-se também pelos princípios da universalidade, da acessibilidade e da coordenação do cuidado, do vínculo e continuidade, da integralidade, da responsabilização, da humanização, e da equidade (Brasil, 2006).

Tagliamento (2012) propõe algumas ações para a efetivação das políticas públicas e legislações vigentes destinadas às mulheres trans e a sua relação com a saúde. Ela propõe as mudanças em três âmbitos: O primeiro é no âmbito da formação disciplinar e da capacitação dos profissionais de saúde sobre a população trans, também em parcerias com ONGs para a sensibilização dos profissionais. As ações no segundo âmbito dizem respeito à organização dos serviços, o que inclui a garantia à mudança do nome civil, a flexibilização dos horários de consultas e exames e a utilização do nome social em todos os veículos de comunicação. O terceiro âmbito diz respeito às ações intersetoriais para a diminuição da discriminação. Alguns exemplos dessas ações são: parcerias das ONGs trans e associações do comércio e indústria para a inclusão dessas pessoas no mercado de trabalho, e o fortalecimento da educação sexual nas escolas (Tagliamento, 2012).

Corroboramos as propostas de mudanças feitas por Tagliamento (2012) nos três âmbitos expostos. Mas reiteramos a importância não só das mudanças de ordem técnica e da capacitação dos profissionais, é preciso ir além e ressignificar o olhar sobre o sujeito que pede atendimento, de acordo com as propostas de um cuidado humanizado, é preciso aceitar o outro enquanto outro. Porém, esse outro geralmente provoca um estranhamento. O momento inicial do encontro de algumas pessoas com uma pessoa transgênera pode ser bastante perturbador, evocando fantasias arcaicas e atualizadas em torno das sexualidades, dos corpos e seus prazeres. A rigidez com que somos constituídos através de uma classificação estrita dos modos masculinos e femininos de ser diante das expressões impede-nos de termos tranquilidade frente às pessoas que apresentam um sexo genital masculino e uma identidade social de gênero feminina. As pessoas travestis embaralham os códigos de inteligibilidade dos gêneros levando os desavisados a uma situação de confusão mental e, quando associados ao moralismo religioso, torna-se disparador poderoso para o exercício da discriminação, exclusão e violência contra as travestis (Peres, 2008).

Teixeira (2005) busca em Espinosa conceitos que podem iluminar essa questão. Ele nos traz o conceito de "zona de comunidade", que seria a descoberta daquilo que nos outros corpos convém ao nosso, e este é apenas o primeiro patamar de uma relação consistente. Ele é também o patamar mais fácil de ser alcançado, e aquele que, talvez, nos dará força para conhecer o que é mais difícil: aquilo que nos outros é diferente e corresponde a sua "zona de singularidade". Porque, para conhecer nos outros corpos, aquilo que não nos convém, é preciso uma potência ainda maior:

E o que temos adiante? Não mais o que no outro se assemelha a nós. Não mais o que é facilmente reconhecível. Não mais o que no outro é, de certa forma, nossa própria imagem espelhada. Mas o que no outro é irredutível. Sua diferença absoluta. Sua singularidade radical. E é aí que começa o verdadeiro desafio da alteridade. Só aí somos verdadeiramente desafiados a aceitar o outro como um legítimo outro. Nessas novas zonas, passamos a experimentar novas intensidades, às quais fomos conduzidos pelos afetos de confiança, mas que já correspondem a novos afetos aumentativos que anunciam, por sua vez, outros modos de existência, em que nos tornamos a causa última de nossas paixões, em que entramos plenamente na posse de nossa potência. Para Espinosa, a liberdade. E o que é esse afeto, essa paixão que nos predispõe a aceitar o outro como um legítimo outro, senão o já mencionado acolhimento? (Teixeira, 2005, p.596).

Como estamos falando de um cuidado em saúde a uma população vista, muitas vezes, através de lentes de preconceitos, os conceitos de "zona de comunidade" e "zona de singularidade" nos fazem pensar. Afinal, quando estamos compartilhando uma zona de comunidade com o outro, esta é uma tarefa muito fácil, porém, conhecer nos outros corpos, aquilo que não nos convém exige uma potência muito maior. Para conseguirmos essa tarefa, podemos olhar para nossas dificuldades e tentarmos enfrentá-las nos ancorando no sentido de nossa prática: o compromisso com o sofrer humano. Aproximar-se da realidade do ser travesti, consiste em um desfio a ser realizado e reivindicado pelas pessoas travestis. Trata-se de uma abertura para o outro humano a sua frente, condição imprescindível para o cuidado humanizado. Como nos traz a fala a seguir:

Porque é fácil você criticar aquilo que você não conhece. A partir do momento que você passa a conhecer aquele objeto ou a pessoa, você já começa a tirar aquela imagem que você tinha. Porque muitas pessoas acham que a travesti só é prostituta, é usuária de drogas, travesti vive na rua, travesti rouba, travesti faz isso e aquilo. $\mathrm{Na}$ verdade, ninguém nunca parou na avenida pra saber porque que elas tão lá. Que que te trouxe você a se prostituir? Que que fez você ficar aqui na rua? Que que fez você tá usando droga? Entendeu? Se muitas vezes você tando num frio daquele você tem que tá bebendo alguma coisa. Você se envolve com as coisas porque é uma necessidade de você sobreviver. É muito fácil você 
jogar pedra naquilo que você não conhece (Fragmento de entrevista - Gisele Bündchen.

Diante do outro que não conhecemos, retomando o conceito de estigma discutido por Goffman (1963/1988), procuramos identificar aspectos que nos permitam prever a sua categoria, transformando-a em expectativas normativas. Dessa forma, um indivíduo que poderia ter sido facilmente recebido por nós em nossas atividades cotidianas é afastado, por possuir um traço diferente das expectativas, destruindo a possibilidade de atenção para outras características suas. Como reflete Gisele, é preciso se permitir conhecer o outro para que preconceitos baseados em estigmas não inviabilizem essa relação.

Em uma concepção hermenêutica de saúde, faz-se necessário adentrar a realidade do sujeito que naquele momento está reclamando atenção. Uma simples pergunta como "O que você acha que pode ser feito por você?" já pode ser uma forma potente de quebrar barreiras entre o saber e o distanciamento profissional do descrédito do sujeito paciente, dando a este participação ativa no processo de recuperação da sua saúde (Ayres, 2007).

E eu acho que se o serviço de saúde, é um grãozinho de areia, mas já é alguma coisa, acho que se a gente conseguir ser respeitada num canto pode ser respeitada em qualquer outro (Fragmento de entrevista - Naomi Campbell).

Cuidar de forma humanizada, nas palavras de Nogueira da Silva (2014, p. 420) destina-se a "dar voz à palavra, à dor, ao riso, ao reencantamento do homem com a tarefa de cuidar de si, de tudo e de todos, na direção de uma vida cúmplice, onde não há salvadores, e sim, a possibilidade de reinventar a vida, o adoecer e o morrer, com o outro", nunca distante dele. Será que a APS será um lugar possível? Se tivermos cuidados com práticas humanizadas, acreditamos que sim!

\section{Conclusão}

O preconceito e as vulnerabilidades enfrentadas pelas pessoas travestis são marcas muito fortes em suas vidas. Elas passam, diariamente, por situações de desrespeito, tendo os seus direitos negligenciados e encontrando vivências de dor e sofrimento. A atenção primária à saúde, por sua vez, é um lugar propício para um cuidado de fato humanizado, em especial o espaço da Estratégia Saúde da Família como um lócus prioritário da APS, no sentido de sua potencialidade em se organizar de acordo com os preceitos do SUS. Se a Estratégia Saúde da Família pode ser um local para humanização do cuidado às pessoas travestis, o respeito abrirá as portas para tal acolhimento.

Depois de apreender um pouco da vivência das pessoas travestis em busca de saúde, podemos compreender as inúmeras dificuldades encontradas nesse percurso. Muito foi construído para um funcionamento mais digno e respeitoso na nossa saúde pública, e muito a de se fazer para operacionalizar de fato os princípios do SUS, as diretrizes da $\mathrm{PNH}$, a fim de se ter uma atenção à saúde passível de ser chamada de humanizada e integral. Porém, a luta pela dignidade, garantia do acesso à saúde das travestis e qualidade do cuidado não passa somente por questões de estruturação do sistema.

Adentrando na vivência de pessoas travestis, descobrimos que as pistas capazes de contribuir para a construção de um cuidado humanizado implicam necessariamente no reconhecimento do outro na qualidade de sujeito de direitos, mas implicam principalmente na presença diante da pessoa em sofrimento que procura um serviço de saúde, do resgate de um profissional cuidador capaz de acolher a diferença em nome do seu compromisso com a dor do outro.

\section{Referências}

Arán, M., Murta, D., \& Lionço, T. (2009). Transexualidade e saúde pública no Brasil. Ciência e Saúde Coletiva, 14(4), 1141-1149.

Ayres, J. R. C. M. (2002). Sobre o risco: para compreender a epidemiologia. 2a Ed, São Paulo: Hucitec.

Ayres, J. R. C. M. (2004). Cuidado e reconstrução das práticas de saúde. Interface - Comunic., Saúde, Educ., 8(14), 73-92.

Ayres, J. R. C.M. (2007). Uma concepção hermenêutica de saúde. PHYSIS: Rev. Saúde Coletiva, 17(1), 43-62.

Ayres, J. R. C. M. (2009). Organização das ações de atenção à saúde. Saúde e Sociedade, 18(2).

Bernini, L. (2011). Macho e fêmea Deus os criou!? A sabotagem transmodernista do sistema binário sexual. Revista Bagoas, 6, 15-47.

Bento, B. (2012). Sexualidade e experiências trans: do hospital à alcova. Ciência $\mathcal{E}$ Saúde Coletiva, 17(10), 2655-2664.

Bittencourt, D., Fonseca, V., \& Segundo, M. (2014). Acesso da população lgbt moradora de favelas aos serviços públicos de saúde: entraves, silêncios e perspectivas. Conexões Psi (Rio de Janeiro), 2 (2), p. 60-85. Disponível em: http://apl.unisuam.edu.br/ revistas/index.php/conexoespsi/article/view/542

Borba, R. (2014). (Des)aprendendo a "ser": trajetórias de socialização e performances narrativas no processo transexualizador. Tese (Doutorado) - Programa Interdisciplinar de Pós Graduação em Linguística Aplicada, Faculdade de Letras, Universidade Federal do Rio de Janeiro. 
Brasil (2006). Portaria $N^{\circ} 675 / G M$, de 30 de março de 2006. Aprova Carta dos Direitos dos Usuários da Saúde, que consolida os direitos e deveres do exercício da cidadania na saúde em todo o país. Diário Oficial da União (Seção I, p. 131), Brasília: Ministério da Saúde.

Brasil (2012). Cadernos HumanizaSUS: Volume 2: Atenção básica. Brasília: Ministério da Saúde. Secretaria de Atenção à Saúde. Núcleo Técnico da Política de Humanização.

Brasil (2016). Política Nacional de Humanização. Acolhimento na gestão e o trabalho em saúde. Brasília, DF: Ministério da Saúde. Secretaria de Atenção à Saúde.

Butler, J. (2002). Cuerpos que Importam: Sobre los Limites Materiales y Discursivos Del Sexo. Buenos Aires: Paidós.

Carvalho, M. (2018). "Travesti”, "mulher transexual”, "homem trans" e "não binário": interseccionalidades de classe e geração na produção de identidades políticas. Cadernos pagu (52), 2018:e185211.

Cerqueira-Santos, E., Calvetti, P. U., Rocha, K. B., Moura, A., Barbosa, L. H., \& Hermel, J. (2010). Percepção de Usuários Gays, Lésbicas, Bissexuais e Transgêneros, Transexuais e Travestis do Sistema Único de Saúde. Revista Interamericana de psicología/Interamerican Journal of Psychology, 44(2), 235-245.

Dumaresq, L. (2016). Ensaio (travesti) sobre a escuta (cisgênera). Periódicus, Salvador, n. 5, v. 1. 121131.

Gadamer, H. G. (2002). Verdade e Método II. Petrópolis: Vozes. (Trabalho original publicado em 1960).

Goffman, E. (1988). Estigma: Notas sobre a manipulação da identidade deteriorada. $4^{\mathrm{a}}$ ed. Rio de Janeiro: LTC. (Trabalho original publicado em 1963).

Gomes, R., Souza, E. R., Minayo, M. C. S., Malaquias, J. V., Silva, C. F. R. (2005). Organização, processamento, análise e interpretação de dados: o desafio da triangulação. Rio de Janeiro: Fiocruz.

Instituto Brasileiro de Geografia e Estatística - IBGE. (2010). Censo Demográfico - 2010. Rio de Janeiro: IBGE. Recuperado em 10 de julho de 2018, de www.ibge.gov.br

Lionço, T. (2008). Que Direito à Saúde para a População GLBT? Considerando Direitos Hmanos, Sexuais e Reprodutivos em Busca da Integralidade e da Eqüidade. Saúde Soc, 17 (2), 11-21.

Mello, G. A., Fontanella, B. J. B., \& Demarzo, M. M. P. (2009). Atenção básica e atenção primária à saúde - origens e diferenças conceituais. Rev. APS, 12(2), 204-213.
Mello, L., Perilo, M., Braz, C. A., \& Pedrosa, C. (2011). Políticas de saúde para lésbicas, gays, bissexuais, travestis e transexuais no Brasil: em busca de universalidade, integralidade e equidade. Sexualidad, Salud y Sociedad, 9, 7-28.

Müller, M. I. (2007). Os médicos nunca me tocaram um dedo! Eu cansei daquele posto!: A percepção das travestis quanto ao atendimento em saúde (Monografia de Especialização). UFRGS: Porto Alegre.

Müller, M. I., \& Knauth, D. R. (2008). Desigualdades no SUS: O caso dos atendimentos às travestis é "babado”! Cadernos Ebape, 6 (2), 1-14.

Nogueira da Silva, G. S. (2014). A Humanização do Cuidado diante da Morte: "Quando a prática queima os dedos”. In L. Pessini, L. Bertachini \& C. P. Barchifontaine (Orgs.), Bioética, cuidado e humanização: sobre o cuidado respeitoso (pp. 405-427). Vol II. São Paulo: Centro Universitário São Camilo: Ediçoes Loyola: IBCC Centro de Estudos.

Pacheco, B. G. C; Rasera, E. F; Prado, M. A. M; Teixeira, F. B. (2017). Psicologias e transexualidades: escritos e escrituras da psicologia brasileira. In: Emerson Fernando Rasera, Maristela de Souza Pereira e Dolores Galindo (Orgs). Democracia participativa, estado e laicidade [recurso eletrônico]: psicologia social e enfrentamentos em tempos de exceção. Porto Alegre: ABRAPSO

Paiva, V. (2005). Analysing sexual esperiences through scenes: a framework for sexualty education and evaluation. London: Sex education March. Pasche, D. F., \& Passos, E. (2008). A importância da humanização a partir do Sistema Único de Saúde. Rev. Saúde públ., 1(1), jan./jun.

Pelúcio, L. (2009) Abjeção e Desejo: uma etnografia travesti sobre o modelo preventivo de AIDS. São Paulo: Annablume, FAPESP.

Peres, W. S. (n.d.). Travestis, Cuidado de Si e Serviços de Saúde: Algumas Reflexões.

Peres, W. S. (2008). Travestis: corpo, cuidado de si e cidadania. Fazendo Gênero 8 - Corpo, Violência e Poder. Florianópolis: de 25 a 28 de agosto de 2008.

Poli Neto, \& Caponi, S. N. C. A. (2007). Medicalização da beleza. Interface - Comunic., Saúde, Educ., 11(23), 569-84.

Red Por La Despatologización De Las Identidades Trans Del Estado Español (2010). Guía de Buenas Prácticas para la Atención Sanitária a Personas Trans em el Marco del Sistema Nacional de Salud. Barcelona. Disponível em http:/www.stp2012.info/ STP-propuesta-sanidad.pdf. Acesso em 04 de março de 2018. 
Romano, V. F. (2008). As Travestis no Programa Saúde da Família da Lapa. Saúde Soc, v.17 (2), 211-219.

Scholze, A. S., Duarte Junior, C. F., \& Silva, Y. F. (2009). Trabalho em saúde e a implantação do acolhimento na atenção primária à saúde: afeto, empatia ou alteridade? Interface comunic., Saude, Educ., 13 (31), 303-14.

Schraiber, L. B. (2012). Necessidades de saúde, políticas públicas e gênero: a perspectiva das práticas profissionais. Ciência \& Saúde Coletiva, 17(10), 2635-2644.

Silva, G. S. N. (2002). AIDS: O adversário que nos reaglutina. In Santos, T.F. (Org.), Saúde Sexual e Reprodutiva: uma abordagem multidisciplinar. Recife: Editora Massangana.

Tagliamento, G. (2012). (In)visibilidades caleidoscópicas: a perspectiva das mulheres trans sobre o seu acesso à saúde integral (Tese de doutorado). Instituto de Psicologia da Universidade de São Paulo.

Teixeira, R. R. (2005). Humanização e atenção primária à saúde. Ciência e Saúde Coletiva, 10(3), 585-597.

Transgender Europe (TGEU). (2016). Trans Murder Monitoring 2016. Acesso em 26 mai de 2016. Disponível em: http://transrespect.org/wp-content/ uploads/2016/11/TvT-PS-Vol14-2016.pdf
Antonia Nathalia Duarte de Moraes (https://orcid. org/0000-0002-4740-6687), possui graduação em Psicologia pela Universidade Estadual da Paraíba. Doutoranda em Psicologia e Mestre em Psicologia pela Universidade Federal do Rio Grande do Norte. Atualmente é professora do Centro Universitário FACEX e da Faculdade Maurício de Nassau. Endereço Institucional: Avenida Abel Cabral, 505. Bloco 3, ap 1005. Bairro: Nova Parnamirim. Cidade: Parnamirim/ RN. CEP: 59151.250. Email: nathaliaduartem@ hotmail.com

Geórgia Sibele Nogueira da Silva (https://orcid. org/0000-0002-5716-6226), possui Graduação em Psicologia pela Universidade de Fortaleza, Mestrado em Saúde Coletiva pela Universidade do Estado do Rio de Janeiro e Doutorado em Ciências Médicas pela Faculdade de Medicina da Universidade de São Paulo. É Professora do Departamento de Psicologia da Universidade Federal do Rio Grande do Norte (UFRN), vinculada ao Programa de Pós-Graduação em Psicologia/PPGPsi. Coordena o Mestrado Profissional em Saúde da Família no Nordeste- MPSF/RENASF núcleo UFRN, e o LETHS - UFRN (Laboratório de Estudos em Tanatologia e Humanização das práticas em Saúde). Email: gsibele@gmail.com

Recebido em 25.02.2018

Primeira Decisão Editorial 06.05.2018

Segunda Decisão Editorial 06.12.2018

Aceito em 27.05.2019 